\title{
Effectiveness of specific stabilization exercise compared with traditional trunk exercise in women with non-specific low back pain: a pilot randomized controlled trial
}

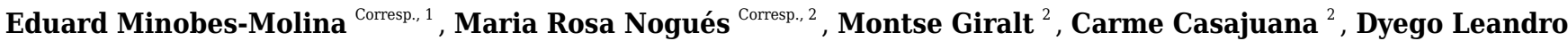 \\ Bezerra de Souza ${ }^{3}$, Javier Jerez-Roig ${ }^{1}$, Marta Romeu ${ }^{2}$ \\ ${ }^{1}$ Research group on Methodology, Methods, Models and Outcomes of Health and Social Sciences- (M3O). Faculty of Health Sciences and Welfare. Centre \\ for Health and Social Care Research (CESS), University of Vic-Central University of Catalonia (UVIC-UCC), Vic, Barcelona, Spain \\ 2 Department of Basic Medical Sciences, Rovira i Virgili University, Reus, Tarragona, Spain \\ 3 Department of Collective Health, Federal University of Rio Grande do Norte, Natal, Rio Grande do Norte, Brazil \\ Corresponding Authors: Eduard Minobes-Molina, Maria Rosa Nogués \\ Email address: eduard.minobes@uvic.cat, mariarosa.nogues@urv.cat
}

Background. Non-specific low back pain (LBP) is the leading cause of disability worldwide. The primary physiotherapeutic treatment for LBP is physical exercise, but evidence suggesting a specific exercise as most appropriate for any given case is limited.

Objective. To determine if specific stabilization exercise (SSE) is more effective than traditional trunk exercise (TTE) in reducing levels of pain, disability and inflammation in women with non-specific low back pain (LBP).

Design. A pilot randomized controlled trial was conducted in Rovira i Virgili University, Catalonia.

Methods. 39 females experiencing non-specific LBP were included in two groups: the TTE program and SSE program, both were conducted by a physiotherapist during twenty sessions. The primary outcome was pain intensity (10-cm Visual Analogue Scale). Secondary outcomes were disability (Roland Morris Disability Questionnaire), and inflammation (IL-6 and TNF- $\alpha$ plasma levels). Measurements were taken at baseline, at half intervention, at post-intervention, and a month later.

Results: Mean group differences in change from baseline to post-intervention for TTE were: -4.5 points (Cl 3.3 to 5.6$)$ for pain, -5.1 points ( $\mathrm{Cl} 3.0$ to 7.3 ) for disability, $0.19 \mathrm{pg} / \mathrm{mL}(95 \% \mathrm{Cl}-1.6$ to 1.2$)$ for IL-6 levels, and $46.2 \mathrm{pg} / \mathrm{mL}(\mathrm{Cl} 13.0$ to 85.3$)$ for TNF- $\alpha$ levels. For SSE, differences were: -4.3 points $(\mathrm{Cl} 3.1$ to 5.6) for pain, -6.1 points ( $\mathrm{Cl} 3.7$ to 8.6 ) for disability, $1.1 \mathrm{pg} / \mathrm{mL}(\mathrm{Cl} 0.0$ to 2.1 ) for IL-6 levels, and 12.8 $\mathrm{pg} / \mathrm{mL}(95 \% \mathrm{Cl}-42.3$ to 16.7$)$ for TNF- $\alpha$ levels. There were an insignificant effect size and no statistically significant overall mean differences between both groups.

Conclusion: This study suggests that both interventions (traditional trunk and specific stabilization exercises) are effective in reducing pain and disability in non-specific LBP patients, but the two programs produce different degrees of inflammation change.

Clinical trial registration number: NCT02103036. 


\section{Effectiveness of specific stabilization exercise compared with \\ 2 traditional trunk exercise in women with non-specific low \\ 3 back pain: a pilot randomized controlled trial}

4 Eduard Minobes-Molina ${ }^{1}$, Maria Rosa Nogués Llort ${ }^{2}$, Montserrat Giralt Batista ${ }^{2}$, Maria del

5 Carmen Casajuana Briansó ${ }^{2}$, Dyego Leandro Bezerra de Souza ${ }^{3}$, Javier Jerez-Roig ${ }^{1}$, Marta

6 Romeu Ferran ${ }^{2}$

7

$8{ }^{1}$ Research group on Methodology, Methods, Models and Outcomes of Health and Social

9 Sciences- $\left(\mathrm{M}_{3} \mathrm{O}\right)$. Faculty of Health Sciences and Welfare. Centre for Health and Social Care

10

11

12

13

14

15

16

17

18

19

20

21

22

23

24

25

26

27

28

29

30

31

32

33

34

35

36

Research (CESS), University of Vic-Central University of Catalonia (UVIC-UCC), Vic, Barcelona, Spain.

${ }^{2}$ Department of Basic Medical Sciences, Rovira i Virgili University, Reus, Tarragona, Spain.

${ }^{3}$ Department of Collective Health, Federal University of Rio Grande do Norte, Natal, Rio

Grande do Norte, Brazil.

Corresponding Author:

Eduard Minobes-Molina ${ }^{1}$

Sagrada Família, 7, 08500 Vic, Barcelona, Spain

Email address: eduard.minobes@uvic.cat

Maria Rosa Nogués Llort ${ }^{2}$

Sant Llorenç Street, 21, 43201 Reus, Tarragona, Spain

Email address: mariarosa.nogues@urv.cat

(1)




\section{Abstract}

38 Background. Non-specific low back pain (LBP) is the leading cause of disability worldwide.

The primary physiotherapeutic treatment for LBP is physical exercise, but evidence suggesting a

Objective. To determine if specific stabilization exercise (SSE) is more effective than traditional trunk exercise (TTE) in reducing levels of pain, disability and inflammation in women with non-

Design. A pilot randomized controlled trial was conducted in Rovira i Virgili University,

\section{Catalonia.}

Methods. 39 females experiencing non-specific LBP were included in two groups: the TTE program and SSE program, both were conducted by a physiotherapist during twenty sessions. The primary outcome was pain intensity (10-cm Visual Analogue Scale). Secondary outcomes were disability (Roland Morris Disability Questionnaire), and inflammation (IL-6 and TNF- $\alpha$ plasma levels). Measurements were taken at baseline, at half intervention, at post-intervention, and a month later.

Results: Mean group differences in change from baseline to post-intervention for TTE were: -4.5 points (CI 3.3 to 5.6) for pain, -5.1 points (CI 3.0 to 7.3 ) for disability, $0.19 \mathrm{pg} / \mathrm{mL}$ (95\% CI -1.6 to 1.2) for IL-6 levels, and $46.2 \mathrm{pg} / \mathrm{mL}$ (CI 13.0 to 85.3) for TNF- $\alpha$ levels. For SSE, differences were: -4.3 points (CI 3.1 to 5.6) for pain, -6.1 points (CI 3.7 to 8.6 ) for disability, $1.1 \mathrm{pg} / \mathrm{mL}$ (CI 0.0 to 2.1$)$ for IL-6 levels, and $12.8 \mathrm{pg} / \mathrm{mL}$ (95\% CI -42.3 to 16.7) for TNF- $\alpha$ levels. There were an insignificant effect size and no statistically significant overall mean differences between both

Conclusion: This study suggests that both interventions (traditional trunk and specific stabilization exercises) are effective in reducing pain and disability in non-specific LBP patients,

\section{Introduction}

Common low back pain (LBP) is defined as pain between the costal margins and the inferior gluteal folds, usually accompanied by painful limitation of movement, often influenced by physical activities and posture, and which may be associated with referred pain in the leg 
is more prevalent in females than males; for example, in 2015 in Catalonia, 30.1\% of females suffered LBP, as compared to $18.7 \%$ of males (Garcia et al., 2016). LBP remains a common disabling condition (Walker et al., 2004) and is associated with high costs for medical health and social care (Haldeman et al., 2012; Wieser et al., 2011).

One of the difficulties in reducing the burden of spinal disorders is the wide and heterogeneous range of specific diseases and non-specific musculoskeletal disorders that can involve the spinal column, most of which manifest pain (Haldeman et al., 2012). Despite this factor, or perhaps because of its impact on individuals, their families, and the healthcare systems, spinal disorders remain one of the most controversial and challenging conditions (Haldeman et al., 2012; D. Hoy et al., 2010).

Back pain is sometimes associated with a likely aetiology (e.g.radiculopathy or spinal stenosis), but most LBP cases are of unknown origin and are classified as non-specific, which has also been described as mechanical pain or strain, account for $90 \%$ or more of all people experiencing spinal pain (Haldeman et al., 2012; M. W. Van Tulder et al., 1997). For all these reasons, it is necessary to find an effective treatment for LBP. Unfortunately, the scientific literature does not offer relevant conclusions, due in part to the poor methodology employed in many published studies - e.g., short follow-up periods, population heterogeneity and non-validated measurements (Atlas \& Nardin, 2003).

According to current clinical reviews and guides, first-line treatments for LBP pathology focus on analgesic measures (Koes et al., 2001; M. Van Tulder et al., 2006). Conservative physiotherapeutic treatments for LBP also exist (Bordas et al., 2004), including advice and postural education, electrotherapy, manual therapy, and physical exercises (Williams et al., 2014). Exercise is one of the chief recommendations for pain reduction, mobility increase, improvement of physical and psychological abilities and anxiety reduction (Waddell \& Burton, 2005). The problem with exercise programs lies in the fact that rationales for choosing the appropriate exercise for an individual case are very weak. Controversy arises because the types of exercise programs for LBP vary considerably, as do the types of patients. This makes it very unlikely that a particular program will be equally effective in all cases (Macedo et al., 2008).

One exercise option is the back school program, a therapeutic program including information on the anatomy of the back, biomechanics, optimal posture, ergonomics, and back exercises (Parreira et al., 2016), which has proven effective in reducing pain and disability (Sahin et al., 2011). There are many types of back school exercise programs, but considerable discussion has centered on the question of whether the specific stabilization exercise program (SSEP) - in which the deep muscles are the protagonists - is preferable to the traditional trunk exercise program (TTEP), which includes more exercises for strengthening abdominal and back muscles. There are systematic reviews that support the idea that SSEP is superior to TTEP (Lederman, 
117 2010), but there are also studies that have found both approaches equally effective for

118

119

120

121

122

123

124

125

126

127

128

129

130

131

132

133

134

135

136

137

138

139

140

141

142

143

144

145

146

147

148

149

150

151

152

153

154

155

156

improvement of LBP in terms of pain and disability (Shamsi et al., 2015).

On the other hand, pro-inflammatory cytokines levels were detected on assessing local tissue in adults with LBP (Queiroz et al., 2015) and evidence shows that physical exercise therapy decreases systemic inflammatory mediators production, this demonstrates its clinical relevance (Pereira et al., 2013).

After years of research into LBP treatment, and taking into account the variety of treatment options, exercise continues to be accepted as an effective approach. The question remains, however, of which type of exercise is most effective in treating various patient subgroups (Atlas $\&$ Nardin, 2003; Saner et al., 2011). There is limited evidence that the specific stabilization exercise program is more effective than the traditional trunk exercise for patients with nonspecific LBP. Therefore, the following were the research questions this study sought to answer:

1. Is the specific stabilization exercise program more effective than the traditional trunk exercise program in reducing levels of pain and disability in women with non-specific LBP? 2. Which type of back school exercise produces different degrees of inflammation change in women with non-specific LBP?

\section{Materials \& Methods}

\section{Ethics}

The Clinical Ethics Committee of University Hospital Sant Joan of Reus approved this study (12-06-28/6proj4). All participants gave written informed consent before data collection began.

\section{Study design}

A pilot randomized trial was conducted in Catalonia from February 2013 to February 2015 (NCT02103036). Participants, diagnosed by medical practitioners and referred for treatment of non-specific LBP, were randomized using computer-generated random number tables into two treatment groups: a TTEP group and a SSEP group (Figure 1). Afterwards, measurements were taken at baseline (session 0), at half intervention (session 10), post-intervention (session 20) and one month later. A single-blind study was conducted, due to the impossibility of achieving double blindness - the physiotherapist performing the intervention had to know which treatment each participant was to receive. The therapist who performed the intervention was a qualified health professional with 5 years' experience in the field; a different professional took all the study measurements, he was blinded to the participant's assignment. Participants were blinded to their group allocation, design and hypotheses (Page \& Persch, 2013).

\section{Participants}

Participants entering the trial were required to meet the following inclusion criteria: females aged 
157 between 18 and 70 years; diagnosed with non-specific LBP (fewer than 6 weeks of pain

158 duration) by a specialist doctor who used imaging such as magnetic resonance, radiographic or

159 computed axial tomography to rule out other spinal disorders, and under no pharmacological

160 treatment for pain. Exclusion criteria were: diagnosed with other spinal disorders and/or any

161 other serious co-morbidities (e.g., cancer, severe lung pathology); presence of cognitive

162 impairment; inability to perform exercises; having followed a specific training program with a

163 physiotherapist in the previous three months; having been treated with analgesic infiltration in

164 the previous 6 weeks, or failure to follow their 20-treatment schedule exactly. All study

165 participants were volunteers, and all underwent intervention under the Faculty of Medicine and

166 Health Sciences of University Rovira i Virgili.

167

168

169

170

171

172

173

174

175

176

177

178

179

180

181

182

183

184

185

186

187

188

189

190

191

192

193

\section{Intervention}

Both treatment groups (TTEP and SSEP) underwent 20 sessions of treatment at a frequency of 3 to 5 sessions per week (Saner et al., 2011), as follows:

In the first 5 sessions, the only treatments were application of an infrared lamp and transcutaneous electrical nerve stimulation (TENS), since these have been proven to reduce pain in both acute and chronic LBP (Bertalanffy et al., 2005; Jauregui et al., 2016; M. Van Tulder et al., 2000). Patients did not perform any exercise in these first sessions, since there is strong evidence that exercise is not effective in relieving acute pain, and can even worsen symptoms (M. Van Tulder et al., 2000). TENS therapy was applied with a multichannel portable TENS unit (Megasonic 313 P4, Carin) on the lumbar spine. Biphasic square wave impulses at a frequency of $100 \mathrm{~Hz}$ and pulse duration of $70 \mu \mathrm{s}$ were used for a total duration of 20 minutes. Four rectangular $90 \times 45-\mathrm{mm}$ electrodes were applied on the fascia thoracolumbaliis and approximately $10 \mathrm{~cm}$ proximal to this, along the midline of the muscle (i.e. directly over the site of pain) (Kofotolis et al., 2008).

In sessions 6 through 20, each group engaged in its respective back school exercise program in regular sessions (Figure 2); they followed 30-minute protocols of 10 exercises, with 10 repetitions of each. The TTEP group performed exercises from the LBP protocol developed by the Physiotherapy and Rehabilitation Service at Sant Joan University Hospital (Reus, Spain). The SSEP group performed exercises gathered in a search of literature on core stability exercises (Koumantakis et al., 2005; Shamsi et al., 2015). Before beginning exercises, participants received education on the anatomy of the back (members of the SSEP received a simplified explanation of core musculature), correct posture, and spinal alignment, as part of a back school. The same physiotherapist supervised all classes. Upon treatment completion, he gave each participant a home exercise program which included the exercises from their treatment sessions.

\section{Outcome measurements}


196 The primary outcome was pain, measured with a 10-cm Visual Analogue Scale (VAS), which 197 has been shown valid and reliable. VAS is a numerical rating scale $(0=$ no pain to $10=$ worst 198 imaginable pain) which represents the intensity of the current pain and allows the evaluator to 199 compare it with previous or later evaluations.(Hawker et al., 2011) VAS was used to measure 200 pain at baseline session 0 and at sessions 10 and 20. Pain measurement one month after the final 201 treatment session was done by telephone, using the 11-point Numerical Rating Scale (NRS). 202 During this phone conversation, each patient also performed a verbal, subjective assessment. 203 Both these final assessments are considered sufficiently sensitive to detect clinically relevant 204 pain changes (Hawker et al., 2011); they are even considered interchangeable for calculating pain in lumbar pathologies (Hawker et al., 2011; Thong et al., 2018; van Tubergen et al., 2002). One secondary outcome was disability, measured using the Roland Morris Disability Questionnaire (RMDQ). The questionnaire asks 24 questions related to the participant's current functional status. Different studies have shown RMDQ to be a useful and reliable instrument for evaluating participants with LBP (Payares et al., 2015). RMDQ was used to measure pain at baseline session 0 , at sessions 10 and 20 , and one month after the final treatment session.

Another secondary outcome was degree of inflammation, as measured by blood-sample levels of the cytokines interleukin 6 (IL-6) and tumor necrosis factor alpha (TNF- $\alpha$ ). These markers were used because they have been found to play significant roles in relation to back pain (De Queiroz et al., 2016; Kraychete et al., 2010). The presence of some inflammatory mediators might be associated with pain and disability in patients with LBP, since pro-inflammatory cytokines such as IL-6 or TNF- $\alpha$ contribute to the activation of nociceptors that generate potential of action and pain hyper sensibility (Cui et al., 2000; Queiroz et al., 2015). Degree of inflammation was measured at the beginning and end of the treatment program by enzyme-linked immunosorbent assay (ELISA) method. Blood samples were collected by a qualified doctor (blinded to group allocation) and will be obtained from the antecubital vein (Tomazoni et al., 2019).

The study recorded additional factors, including anthropometric characteristics (age, height, weight, body mass index [BMI]), and degree of physical activity using Quick Classifier of Physical Activity (ClassAF) in Metabolic Equivalent of Tasks (METs). ClassAF is a global questionnaire which classifies people as physically active or inactive using a corresponding qualitative formula (Vallbona et al., 2007). All these data were collected before the intervention began by the trained physiotherapist.

\section{Data analysis}

232

Groups were compared with respect to change, from baseline (session 0 ) to half-intervention (session 10), baseline to post-intervention (session 20), and baseline to 1 month after the intervention concluded; from session 10 to session 20 and session 10 to one month post intervention; and finally from session 20 to one month post intervention. 
236

237

238

239

240

241

242

243

244

245

246

247

248

249

250

251

252

253

254

255

256

257

258

259

260

261

262

263

264

265

266

267

268

269

270

271

272

273

274

275

SPSS program version 23 Windows was used to analyze the data. A descriptive analysis was made of the study sample, with standard averages, deviations and percentages of the different variables collected. The Kolmogórov-Smirnov test was applied to assess data distribution in each group. A Student-t test was done to assess differences between the two treatments, and effect size was calculated to measure the magnitude of the experimenter effect, using the standardized mean difference (SMD) for variables normally distributed and the effect size of Mann-Whitney's $\mathrm{U}$ test for variables not normally distributed (Field, 2005). Two-way repeated ANOVA analyses were used to examine differences over time. Assessments were carried out using non-parametric tests for variables that did not present normal distributions. The level of statistical significance for the study was established at $p<0.05$.

\section{Results}

\section{Flow of participants and therapists through the trial}

59 potential participants were referred to the research team. Of those referred, 20 were not included, for various reasons (Figure 1). 20 participants were placed in the traditional trunk exercise group (TTEP); the remaining 19 were placed the specific stabilization exercise group (SSEP). Of these 39 participants, 30 completed their course of treatment (15 from each group). Table 1 shows participants' baseline characteristics: age, height, weight, BMI, physical activity level, pain or disability. According to the CONSORT statement, significance testing of baseline differences in randomized controlled trials were not performed (Moher et al., 2010). Two members of the SSEP group could not be reached for the one-month follow-up telephone call.

\section{Compliance with the trial method}

$30(76,9 \%)$ participants attended all 20 intervention sessions. Once the intervention was completed, the physiotherapist advised participants to repeat their exercises at home, three times a week for one month. 15 (50\%) participants reported performing the exercises as advised; 9 (30\%) reported doing their exercises occasionally; 4 (13.3\%) did not perform exercises at home; the remaining $2(6,67 \%)$ were unreachable.

\section{Effect of intervention}

Data on pain and disability are shown in Table 2; data on degree of inflammation are in Figure 3 and Figure 4.

Results show an insignificant effect size and no significant differences between groups in terms of current pain intensity, or for any outcome measure. At the end of intervention (session 20), pain intensity for the TTEP group had decreased by $0.33 \mathrm{~cm}(95 \% \mathrm{CI}-1.7$ to $1.0, p=0.615)$ more than in the SSEP group. Both back school treatments showed positive results for pain reduction from baseline to end of treatment, and baseline to one month post-intervention. In the TTEP group, pain (baseline to final session) reduced by $4.6 \mathrm{~cm}(95 \%$ CI 3.3 to 5.8); the SSEP group's

Peer) reviewing PDF | (2020:05:48820:2:1:NEW 9 Oct 2020) 
276

277

278

279

280

281

282

283

284

285

286

287

288

289

290

291

292

293

294

295

296

297

298

299

300

301

302

303

304

305

306

307

308

309

310

311

312

313

314

315

reduction was $4.3 \mathrm{~cm}(95 \%$ CI 3.0 to 5.6$)$.

Similarly, there were an insignificant effect size and no significant differences between groups in terms of change in disability. At post-intervention (session 20), disability levels in the SSEP group had decreased by 0.40 points $(95 \%$ CI -1.7 to $2.5, p=0.701)$ more than the TTEP group. Both back school treatments yielded positive results in disability reduction, baseline to end of treatment, and baseline to one month post-treatment. In the TTEP group, RMDQ scores reduced by 5.1 points (95\% CI 3.0 to 7.3 ) from baseline to post-intervention. In the SSEP group, RMDQ reduction for the same interval was 6.1 points (95\% CI 3.7 to 8.6$)$.

Figure 3 and Figure 4 show outcomes for inflammation. TNF- $\alpha$ showed higher values for the TTEP group than the SSEP group at the two visits where TNF- $\alpha$ was measured. Significant differences were observed between the groups, baseline and post-treatment. In the first case, a difference of $66.97 \mathrm{pg} / \mathrm{mL}$ (95\% CI 6.3 to 139.5) was recorded; in the second case the difference was $128.94 \mathrm{pg} / \mathrm{mL}$ (95\% CI 52.8 to 205.0$)$.

In contrast, IL-6 levels were found to be similar between the two treatment groups, with no significant differences observed. At baseline the difference was $2.51 \mathrm{pg} / \mathrm{mL}$ (95\% CI -2.3 to 7.3); at post-intervention the difference was $1.25 \mathrm{pg} / \mathrm{mL}(95 \% \mathrm{CI}-3.9$ to 6.4$)$.

In reference to the evolution of inflammatory biomarkers between baseline and post-treatment, the results for participants who practiced traditional TTEP indicate an increase in TNF- $\alpha$ levels of $46.16 \mathrm{pg} / \mathrm{mL}$ (95\% CI 13.0 to 85.3$)$ and a tendency toward decreased levels of IL-6, 0.19 $\mathrm{pg} / \mathrm{mL}(95 \% \mathrm{CI}-1.6$ to 1.2$)$.

In contrast, the results in the group that practiced SSEP are the other way around: there was an increase in IL-6 levels of $1.06 \mathrm{pg} / \mathrm{mL}$ (95\% CI 0.03 to 2.1$)$ and a tendency toward decrease in TNF- $\alpha$ levels of $12.81 \mathrm{pg} / \mathrm{mL}$ (95\% CI -42.3 to 16.7$)$.

\section{Discussion}

Our study hypothesis suggested that treatment with SSEP would be found to decrease pain and disability more effectively than TTEP, in women with non-specific LBP. We found this hypothesis not entirely true - although the effectiveness of SSEP was apparently demonstrated, the effectiveness of TTEP was found to be quite similar in our study group.

The literature documents study results confirming those of our own study: Shamsi et al., also concluded that the two types of exercise provide improvement in LBP, but found no evidence as to which type might be more effective (Shamsi et al., 2015).

The literature also includes meta-analyses comparing back schools for chronic LBP. These found deep-muscle exercises more effective in reducing short-term pain and disability (Chang et al., 2015; Niederer \& Mueller, 2020; Wang et al., 2012), though they found no significant 
316

317

318

319

320

321

322

323

324

325

326

327

328

329

330

331

332

333

334

335

336

337

338

339

340

341

342

343

344

345

346

347

348

349

350

351

352

353

354

355

differences in long-term improvement. In our study, however, after the half-way point in treatment (session 10) we observed pain reduction by both modalities. We believe this was most likely due to the fact that participants in the meta-analyzed clinical trials suffered from chronic lower back pain, which has a worse prognosis than non-specific LBP in an early phase (Van Den Hoogen et al., 1998).

Contrary to our results, in a recent systematic review, a meta-analysis of 8 studies indicated that stabilization exercises were more effective than general exercises in reducing pain. Five studies demonstrated a significant improvement in disability between patients treated with stabilization exercises compared with those treated with general exercises (Gomes-Neto et al., 2017). In our case, the SSEP and TTEP seem to be effective in reducing pain and improving disability. The mean of pain in the analyzed studies was 6.01 at baseline, being 2.1 at the end of the stabilization exercises on a $0-10$ pain scale (GomesNeto et al., 2017). The SSEP results of our trial are consistent with these findings: 6.53 at baseline and 2.2 at the end of the intervention.

There are authors who have found that stabilizing treatment shows no significant advantage over traditional treatment (Koumantakis et al., 2005); some of these authors believe that where there appears to be such an advantage, it is due to certain characteristics of the LBP patients involved, such as segmental instability of the column, or the size of the multifidus muscles. One of the exclusion criteria in our study was diagnosis of other spinal disorders, so our sample was more homogeneous.

Our results with regard to inflammation indicate that, following TTEP, TNF- $\alpha$ levels had increased; when SSEP was used, IL-6 levels had increased by the end of our 20-session course of treatment.

Al-Obaid et al., recently reported on a study with characteristics similar to ours, which found increased production of pro-inflammatory cytokine TNF- $\alpha$ after treatment, but no change in IL-6 production (Al-Obaidi \& Mahmoud, 2014). The author justified this result by stating that overexpression of TNF- $\alpha$ and other pro-inflammatory cytokines occurs in many studies of lowback pathologies (Takahashi et al., 1996). In addition, he explained, IL-6 cytokine levels are not altered because IL-6 has both pro-inflammatory and anti-inflammatory properties (Opal \& Depalo, 2000).

Various studies claim that IL-6 acts predominantly as an anti-inflammatory cytokine, regulating the synthesis of pro-inflammatory cytokines IL-1 and TNF- $\alpha$ and stimulating the appearance, in circulation, of anti-inflammatory cytokines such as IL-10 (Opal \& Depalo, 2000; Saavedra Ramírez et al., 2011). One study goes further (Petersen \& Pedersen, 2005), claiming that IL-6 stimulates lipolysis and oxidation of fats, as well as producing anti-inflammatory effects during exercise - and therefore may offer protection against TNF- $\alpha$. Relating this information to our own findings, we could say that treatment with SSEP aims to be more effective because, in our case, TNF- $\alpha$ levels were maintained while IL-6 increased. On the other hand, with TTEP the reverse was true: the cytokine found to have increased in the plasma was TNF- $\alpha$.

We believe this is due to the nature of the exercises. In SSEP, deep muscle exercise is the basis 
356

357

358

359

360

361

362

363

364

365

366

367

368

369

370

371

372

373

374

375

376

377

378

379

380

381

382

383

384

385

386

387

388

389

390

391

392

393

394

395

of lumbar and segmental control stabilization. TTEP, on the other hand, focuses on building overall muscle resistance, strength and flexibility, being a more dynamic and intense activity. The literature includes findings that lower-intensity exercises are more effective than those of greater intensity, when it comes to reducing inflammation (Ghafourian et al., 2016).

One of our study's limitations is its sample size, but we also prioritized for this pilot trial the homogeneity of our patients through strict inclusion and exclusion criteria, for example we only studied women due their physiological characteristics such as less muscle and bone mass as well as psychological factors (Damian Hoy et al., 2012). A study design with larger samples would allow a greater effect size between groups and the creation of subgroups according to age, degree of physical activity, or BMI - facilitating more definitive conclusions regarding these factors. Further, we believe it would be interesting to add another follow-up, beyond this study's onemonth-post-intervention evaluation. Further follow-up (at six months, for example) would reveal any difference between the treatments in terms of long-term clinical improvement, although the results of the current literature suggest that SSEP improves pain and functional status at 3 months but not at 6 or 12 months (Coulombe et al., 2017).

In summary, this study suggests that any type of back school exercise is highly effective in reducing pain and reducing disability in women with non-specific LBP. Further, it showed that SSEP seems to have an anti-inflammatory effect in such patients, potentially offering protection against chronic diseases associated with low-grade inflammation (Petersen \& Pedersen, 2005).

\section{Conclusions}

This study adds to the literature the finding that both back school exercise program are apparently effective and equivalent in reducing pain and improving disability in women with non-specific LBP, from the tenth treatment session to one month after intervention. Moreover, it demonstrates the influence of each back school in the degree of inflammation, concluding that SSEP seems to increase production of anti-inflammatory biomarkers, while TTEP increases proinflammatory biomarker production. A large, adequately powered study is recommended to determine if the results from this pilot study can be duplicated.

\section{Acknowledgements}

We thank all patients for their participation in this study. Furthermore, we thank the physiotherapists Iris Alonso, Idoia Garitano and Cristina Pellicer for the collaboration.

\section{References}

Al-Obaidi, S., \& Mahmoud, F. (2014). Immune responses following McKenzie lumbar spine exercise in individuals with acute low back pain: a preliminary study. Acta Med Acad. https://doi.org/10.5644/ama2006-124.96

Atlas, S. J., \& Nardin, R. A. (2003). Evaluation and treatment of low back pain: An evidencebased approach to clinical care. Muscle \& Nerve. https://doi.org/10.1002/mus.10311 
396

397

398

399

400

401

402

403

404

405

406

407

408

409

410

411

412

413

414

415

416

417

418

419

420

421

422

423

424

425

426

427

428

429

430

431

432

433

434

435

436

437

438

439

440

441

Bertalanffy, A., Kober, A., Bertalanffy, P., Gustorff, B., Gore, O., Adel, S., \& Hoerauf, K. (2005). Transcutaneous electrical nerve stimulation reduces acute low back pain during emergency transport. In Acad Emerg Med. https://doi.org/10.1197/j.aem.2005.01.013

Bordas, J. M., Forcada, J., Garcia, J. A., Joaniquet, X., Pellisé, F., Mazeres, O., Prat, N., \& Romera, M. (2004). Patologia de la columna lumbar en l'adult. Direcció clínica en l'atenció primària. Guies de pàctica clínica: material docent. Generalitat de Catalunya. Institut Català de la Salut. 1-49. https://www.gencat.cat/ics/professionals/guies/docs/guia_lumbalgies.pdf

Chang, W. D., Lin, H. Y., \& Lai, P. T. (2015). Core strength training for patients with chronic low back pain. J Phys Ther Sci. https://doi.org/10.1589/jpts.27.619

Coulombe, B. J., Games, K. E., Neil, E. R., \& Eberman, L. E. (2017). Core stability exercise versus general exercise for chronic low back pain. Journal of Athletic Training. https://doi.org/10.4085/1062-6050-51.11.16

Cui, J. G., Holmin, S., Mathiesen, T., Meyerson, B. A., \& Linderoth, B. (2000). Possible role of inflammatory mediators in tactile hypersensitivity in rat models of mononeuropathy. Pain. https://doi.org/10.1016/S0304-3959(00)00331-6

De Queiroz, B. Z., Pereira, D. S., Lopes, R. A., Felício, D. C., Silva, J. P., De Britto Rosa, N. M., Dias, J. M. D., Dias, R. C., Lustosa, L. P., \& Pereira, L. S. M. (2016). Association between the plasma levels of mediators of inflammation with pain and disability in the elderly with acute low back pain: Data from the Back Complaints in the Elders (BACE)-Brazil study. Spine. https://doi.org/10.1097/BRS.0000000000001214

Field, A. (2005). Discovering statistics using SPSS (2nd ed.). In Discovering statistics using SPSS (2nd ed.).

Garcia, O., Medina, A., \& Schiafinno, A. (2016). Enquesta de Salut de Catalunya. Comportaments relacionats amb la salut, l'estat de salut i l'ús dels serveis sanitaris a Catalunya. Informe dels principals resultats 2015 (Direcció General de Planificació en Salut (ed.); 1a ed.). Generalitat de Catalunya. Departament de Salut. salutweb.gencat.cat/esca

Ghafourian, M., Ashtary-Larky, D., Chinipardaz, R., Eskandary, N., \& Mehavaran, M. (2016). Inflammatory Biomarkers' Response to Two Different Intensities of a Single Bout Exercise Among Soccer Players. Iran Red Crescent Med J. https://doi.org/10.5812/ircmj.21498

Gomes-Neto, M., Lopes, J. M., Conceição, C. S., Araujo, A., Brasileiro, A., Sousa, C., Carvalho, V. O., \& Arcanjo, F. L. (2017). Stabilization exercise compared to general exercises or manual therapy for the management of low back pain: A systematic review and metaanalysis. In Physical Therapy in Sport. https://doi.org/10.1016/j.ptsp.2016.08.004

Haldeman, S., Kopansky-Giles, D., Hurwitz, E. L., Hoy, D., Mark Erwin, W., Dagenais, S., Kawchuk, G., Strömqvist, B., \& Walsh, N. (2012). Advancements in the management of spine disorders. Best Practice and Research: Clinical Rheumatology, 26(2), 263-280. https://doi.org/10.1016/j.berh.2012.03.006

Hawker, G. A., Mian, S., Kendzerska, T., \& French, M. (2011). Measures of adult pain: Visual Analog Scale for Pain (VAS Pain), Numeric Rating Scale for Pain (NRS Pain), McGill Pain Questionnaire (MPQ), Short-Form McGill Pain Questionnaire (SF-MPQ), Chronic Pain Grade Scale (CPGS), Short Form-36 Bodily Pain Scale (SF. Arthritis Care and Research, 63(SUPPL. 11). https://doi.org/10.1002/acr.20543

Hoy, D., Brooks, P., Blyth, F., \& Buchbinder, R. (2010). The Epidemiology of low back pain. In Best Practice and Research: Clinical Rheumatology. 
https://doi.org/10.1016/j.berh.2010.10.002

Hoy, Damian, Bain, C., Williams, G., March, L., Brooks, P., Blyth, F., Woolf, A., Vos, T., \& Buchbinder, R. (2012). A systematic review of the global prevalence of low back pain. In Arthritis and Rheumatism. https://doi.org/10.1002/art.34347

Jauregui, J. J., Cherian, J. J., Gwam, C. U., Chughtai, M., Mistry, J. B., M., Elmallah, R. K., Harwin, S. F., Bhave, A., \& Mont, M. A. (2016). A Meta-Analysis of Transcutaneous Electrical Nerve Stimulation for Chronic Low Back Pain. Surgical Technology International.

Koes, B. W., van Tulder, M. W., Ostelo, R., Kim Burton, a, \& Waddell, G. (2001). Clinical guidelines for the management of low back pain in primary care: an international comparison. Spine. https://doi.org/10.1097/00007632-200111150-00022

Kofotolis, N. D., Vlachopoulos, S. P., \& Kellis, E. (2008). Sequentially allocated clinical trial of rhythmic stabilization exercises and TENS in women with chronic low back pain. Clinical Rehabilitation. https://doi.org/10.1177/0269215507080122

Koumantakis, G. A., Watson, P. J., \& Jacqueline, A. (2005). Research Report Trunk Muscle Stabilization Training Plus General Exercise Versus General Exercise Only : Randomized Controlled Trial of Patients With. Physical Therapy.

Kovacs, F. M., Fernández, C., Cordero, A., Muriel, A., González-Luján, L., \& Gil Del Real, M. T. (2006). Non-specific low back pain in primary care in the Spanish National Health Service: A prospective study on clinical outcomes and determinants of management. BMC Health Services Research. https://doi.org/10.1186/1472-6963-6-57

Kraychete, D. C., Sakata, R. K., Issy, A. M., Bacellar, O., Santos-Jesus, R., \& Carvalho, E. M. (2010). Serum cytokine levels in patients with chronic low back pain due to herniated disc: analytical cross-sectional study. Sao Paulo Medical Journal = Revista Paulista de Medicina, 128(5), 259-262. https://doi.org/10.1590/S1516-31802010000500003

Lederman, E. (2010). The myth of core stability. Journal of Bodywork and Movement Therapies, 14(1), 84-98. https://doi.org/10.1016/j.jbmt.2009.08.001

Macedo, L. G., Latimer, J., Maher, C. G., Hodges, P. W., Nicholas, M., Tonkin, L., McAuley, J. H., \& Stafford, R. (2008). Motor control or graded activity exercises for chronic low back pain? A randomised controlled trial. BMC Musculoskelet Disord. https://doi.org/10.1186/1471-2474-9-65

Moher, D., Hopewell, S., Schulz, K. F., Montori, V., Gøtzsche, P. C., Devereaux, P. J., Elbourne, D., Egger, M., \& Altman, D. G. (2010). CONSORT 2010 Explanation and Elaboration: updated guidelines for reporting parallel group randomised trials. Journal of Clinical Epidemiology. https://doi.org/10.1016/j.jclinepi.2010.03.004

Niederer, D., \& Mueller, J. (2020). Sustainability effects of motor control stabilisation exercises on pain and function in chronic nonspecific low back pain patients: A systematic review with meta-analysis and meta-regression. In PLOS ONE. https://doi.org/10.1371/journal.pone.0227423

Opal, S. M., \& Depalo, V. A. (2000). Impact of basic research on tomorrow's medicine: antiinflammatory cytokines. CHEST. https://doi.org/10.1378/chest.117.4.1162

Page, S. J., \& Persch, A. C. (2013). Recruitment, retention, and blinding in clinical trials. American Journal of Occupational Therapy. https://doi.org/10.5014/ajot.2013.006197

Parreira, P., Heymans, M. W., van Tulder, M. W., Esmail, R., Koes, B. W., Poquet, N., Lin, C.W. C., Maher, C. G., Cwc, L., Mw, H., Mw, V. T., Esmail, R., Bw, K., Cg, M., \& Report, O. (2016). DOES NOT RE-ESTABLISH WALKING IN NON-WALKING SUBJECTS 
WITH. The Cochrane Database of Systematic Reviews. https://doi.org/10.2340/165019772508

Payares, K., Lugo, L. H., \& Restrepo, A. (2015). Validation of the Roland Morris Questionnaire in Colombia to Evaluate Disability in Low Back Pain. Spine. https://doi.org/10.1097/BRS.0000000000000963

Pereira, D. S., Mateo, E. C. C., De Queiroz, B. Z., Assumpção, A. M., Miranda, A. S., Felício, D. C., Rocha, N. P., Da Cruz Dos Anjos, D. M., Pereira, D. A. G., Teixeira, A. L., \& Pereira, L. S. M. (2013). TNF- $\alpha$, IL6, and IL10 polymorphisms and the effect of physical exercise on inflammatory parameters and physical performance in elderly women. Age. https://doi.org/10.1007/s11357-013-9515-1

Petersen, A., \& Pedersen, B. (2005). The anti-inflammatory effect of exercise. Journal of Applied Physiology. https://doi.org/10.1152/japplphysiol.00164.2004

Queiroz, B. Z., Pereira, D. S., De Britto Rosa, N. M., Lopes, R. A., Felício, D. C., Pereira, D. G., Dias, J. M. D., Dias, R. C., \& Pereira, L. S. M. (2015). Functional performance and plasma cytokine levels in elderly women with and without low back pain. Journal of Back and Musculoskeletal Rehabilitation. https://doi.org/10.3233/BMR-140526

Saavedra Ramírez, P. G., Vásquez Duque, G. M., \& González Naranjo, L. A. (2011). Interleucina-6: ¿amiga o enemiga? Bases para comprender su utilidad como objetivo terapéutico. Iatreia.

Sahin, N., Albayrak, I., Durmus, B., \& Ugurlu, H. (2011). Effectiveness of back school for treatment of pain and functional disability in patients with chronic low back pain: A randomized controlled trial. J Rehabil Med. https://doi.org/10.2340/16501977-0650

Saner, J., Kool, J., De Bie, R. A., Sieben, J. M., \& Luomajoki, H. (2011). Movement control exercise versus general exercise to reduce disability in patients with low back pain and movement control impairment. A randomised controlled trial. BMC Musculoskeletal Disorders. https://doi.org/10.1186/1471-2474-12-207

Shamsi, M., Sarrafzadeh, J., \& Jamshidi, A. (2015). Comparing core stability and traditional trunk exercise on chronic low back pain patients using three functional lumbopelvic stability tests. In Physiotherapy theory and practice. https://doi.org/10.3109/09593985.2014.959144

Takahashi, H., Suguro, T., Okazima, Y., Motegi, M., Okada, Y., \& Kakiuchi, T. (1996). Inflammatory cytokines in the herniated disc of the lumbar spine. Spine. https://doi.org/10.1097/00007632-199601150-00011

Thong, I. S. K., Jensen, M. P., Miró, J., \& Tan, G. (2018). The validity of pain intensity measures: What do the NRS, VAS, VRS, and FPS-R measure? Scandinavian Journal of Pain. https://doi.org/10.1515/sjpain-2018-0012

Tomazoni, S. S., Costa, L. O. P., Joensen, J., Stausholm, M. B., Naterstad, I. F., Leal-Junior, E. C. P., \& Bjordal, J. M. (2019). Effects of photobiomodulation therapy on inflammatory mediators in patients with chronic non-specific low back pain: Protocol for a randomized placebo-controlled trial. Medicine (United States). https://doi.org/10.1097/MD.0000000000015177

Vallbona, C., Roure, E., Violan, M., \& Alegre, J. (2007). Guia de prescripció d'exercici fisic per a la salut (PEFS) (D. de S. Direcció General de Salut Pública \& D. de la V. Secretaria General de l'Esport (eds.); 1a ed.).

Van Den Hoogen, H. J. M., Koes, B. W., Th, J., Van Eijk, M., Bouter, L. M., \& Devillé, W. (1998). On the course of low back pain in general practice: a one year follow up study. Ann 
534

535

536

537

538

539

540

541

542

543

544

545

546

547

548

549

550

551

552

553

554

555

556

557

558

559

560

561

562

563

564

565

566

567

568

569

Rheum Dis. https://doi.org/10.1136/ard.57.1.13

van Tubergen, A., Debats, I., Ryser, L., Londoño, J., Burgos-Vargas, R., Cardiel, M. H., Landewé, R., Stucki, G., \& Van der Heijde, D. (2002). Use of a numerical rating scale as an answer modality in ankylosing spondylitis-specific questionnaires. Arthritis Care \& Research, 47(3), 242-248. https://doi.org/10.1002/art.10397

Van Tulder, M., Becker, A., Bekkering, T., Breen, A., Del Real, M. T. G., Hutchinson, A., Koes, B., Laerum, E., \& Malmivaara, A. (2006). Chapter 3: European guidelines for the management of acute nonspecific low back pain in primary care. European Spine Journal, 15(SUPPL. 2), 169-191. https://doi.org/10.1007/s00586-006-1071-2

Van Tulder, M., Malmivaara, A., Esmail, R., \& Koes, B. (2000). Exercise therapy for low back pain: A systematic review within the framework of the cochrane collaboration back review group. Spine. https://doi.org/10.1097/00007632-200011010-00011

Van Tulder, M. W., Assendelft, W. J. J., Koes, B. W., \& Bouter, L. M. (1997). Spinal radiographic findings and nonspecific low back pain: A systematic review of observational studies. Spine. https://doi.org/10.1097/00007632-199702150-00015

Waddell, G., \& Burton, A. K. (2005). Concepts of rehabilitation for the management of low back pain. Best Pract Res Clin Rheumatol. https://doi.org/10.1016/j.berh.2005.03.008

Walker, B. F. (2000). The prevalence of low back pain: A systematic review of the literature from 1966 to 1998. In Journal of Spinal Disorders. https://doi.org/10.1097/00002517200006000-00003

Walker, B. F., Muller, R., \& Grant, W. D. (2004). Low back pain in Australian adults. health provider utilization and care seeking. J Manipulative Physiol Ther. https://doi.org/10.1016/j.jmpt.2004.04.006

Wang, X., Zheng, J., Yu, Z., Bi, X., Lou, S., Liu, J., Cai, B., Hua, Y., Wu, M., Wei, M., Shen, H., Chen, Y., Pan, Y., Xu, G., \& Chen, P. (2012). A meta-analysis of core stability exercise versus general exercise for chronic low back pain. PloS One. https://doi.org/10.1371/journal.pone.0052082

Wieser, S., Horisberger, B., Schmidhauser, S., Eisenring, C., Brügger, U., Ruckstuhl, A., Dietrich, J., Mannion, A. F., Elfering, A., Tamcan, Ö., \& Müller, U. (2011). Cost of low back pain in Switzerland in 2005. European Journal of Health Economics, 12(5), 455-467. https://doi.org/10.1007/s10198-010-0258-y

Williams, C. M., Maher, C. G., Latimer, J., McLachlan, A. J., Hancock, M. J., Day, R. O., \& Lin, C. W. C. (2014). Efficacy of paracetamol for acute low-back pain: A double-blind, randomised controlled trial. The Lancet, 384(9954), 1586-1596. https://doi.org/10.1016/S0140-6736(14)60805-9 
Figure 1

Design and flow of participants through the trial. 


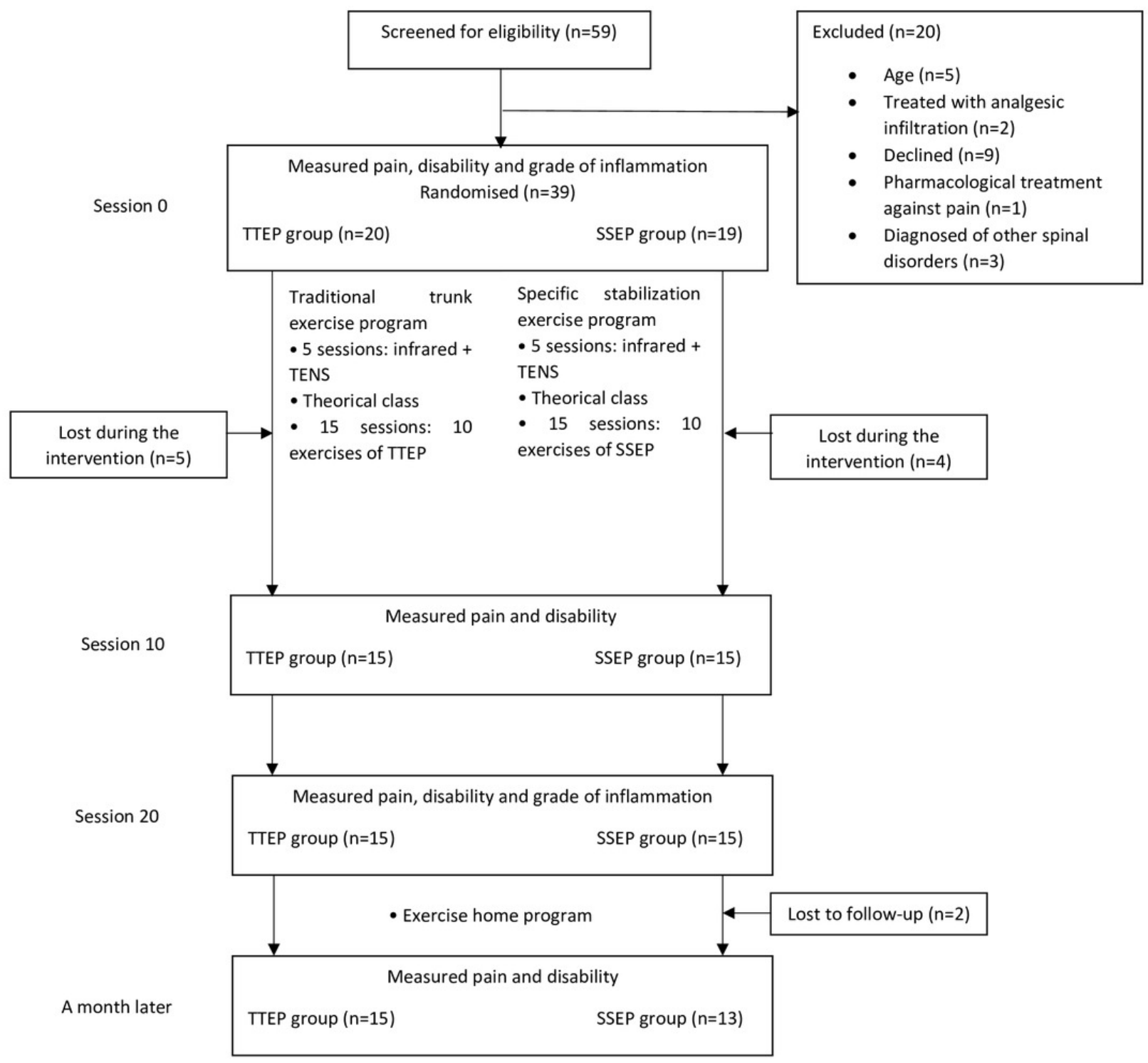


Figure 2

Progress of the exercise programs. 


\begin{tabular}{|c|c|c|}
\hline & $\begin{array}{c}\text { Traditional trunk exercise } \\
\text { Muscles involved: global abdominal } \\
\text { and back muscles }\end{array}$ & $\begin{array}{c}\text { Specific stabilization exercise } \\
\text { Muscles involved: deep muscles } \\
\text { (transversus abdominis, multifidus and } \\
\text { internal oblique muscles) }\end{array}$ \\
\hline 1 & & 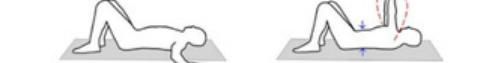 \\
\hline 2 & $\widehat{A=3}$ हत & $\sqrt{1} 3$ \\
\hline 3 & & \\
\hline 4 & & \\
\hline 5 & & 3 \\
\hline 6 & & \\
\hline 7 & 3 & \\
\hline 8 & 1 & \\
\hline 9 & $\Leftrightarrow \quad f$ & $\mathscr{r a}$ \\
\hline 10 & \&na & $g \bumpeq$ \\
\hline
\end{tabular}




\section{Figure 3}

Mean (SD) TNF- $\alpha$ biomarker levels in TTEP group and SSEP group at baseline (session 0) and post-intervention (session 20).

TNF- $\alpha=$ tumour necrosis factor alpha; TTEP $=$ traditional trunk exercise program; SSEP $=$ specific stabilization exercise program; $A=$ Significant difference between baseline and postintervention in TTEP group. $a=$ Significant difference between baseline groups. $b=$ Significant difference between post-intervention groups. 


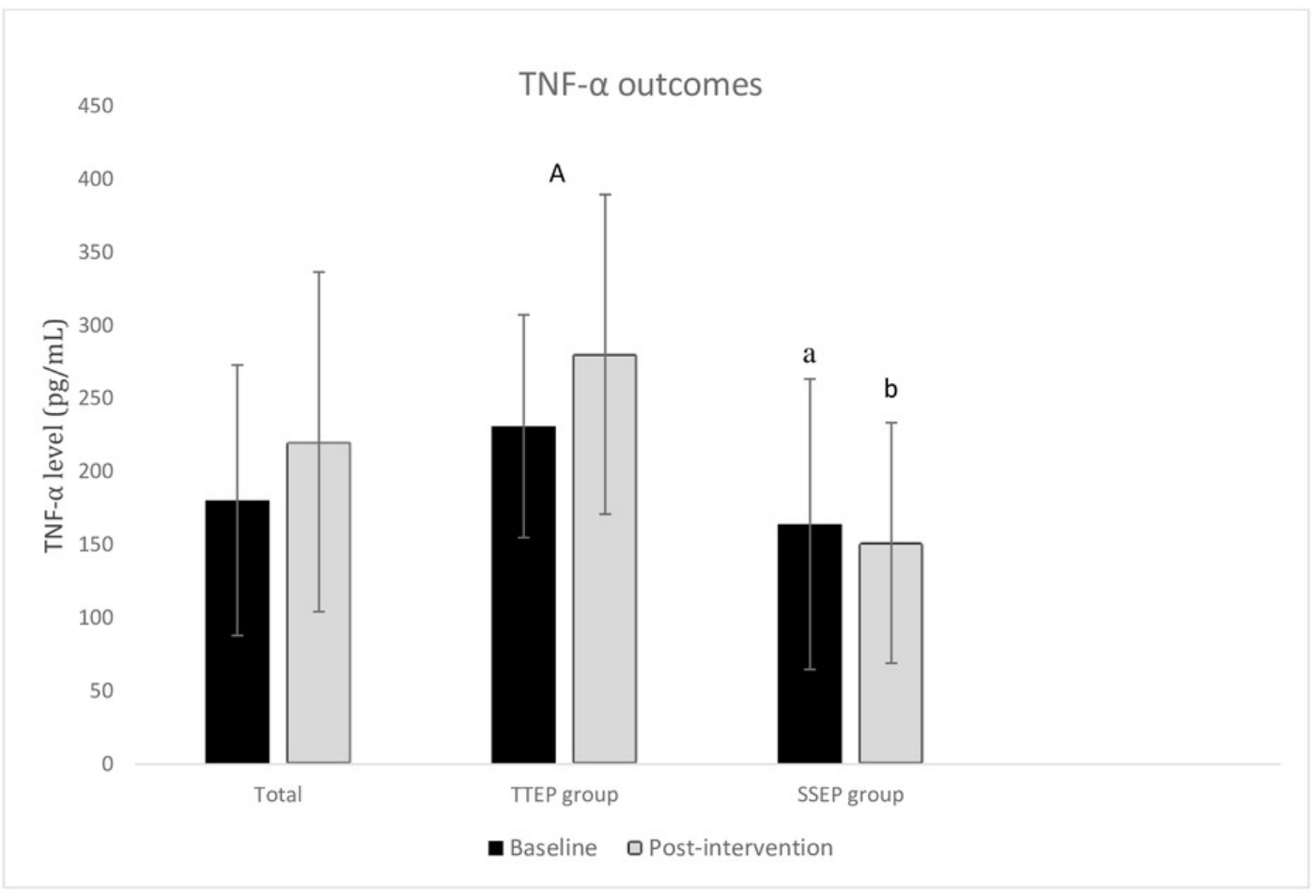


Figure 4

Mean (SD) IL-6 biomarker levels in TTEP group and SSEP group at baseline (session 0) and post-intervention (session 20).

IL-6 = interleukin 6; TTEP = traditional trunk exercise program; SSEP = specific stabilization exercise program; $\mathrm{B}=$ Significant difference between baseline and post-intervention in SSEP group. 


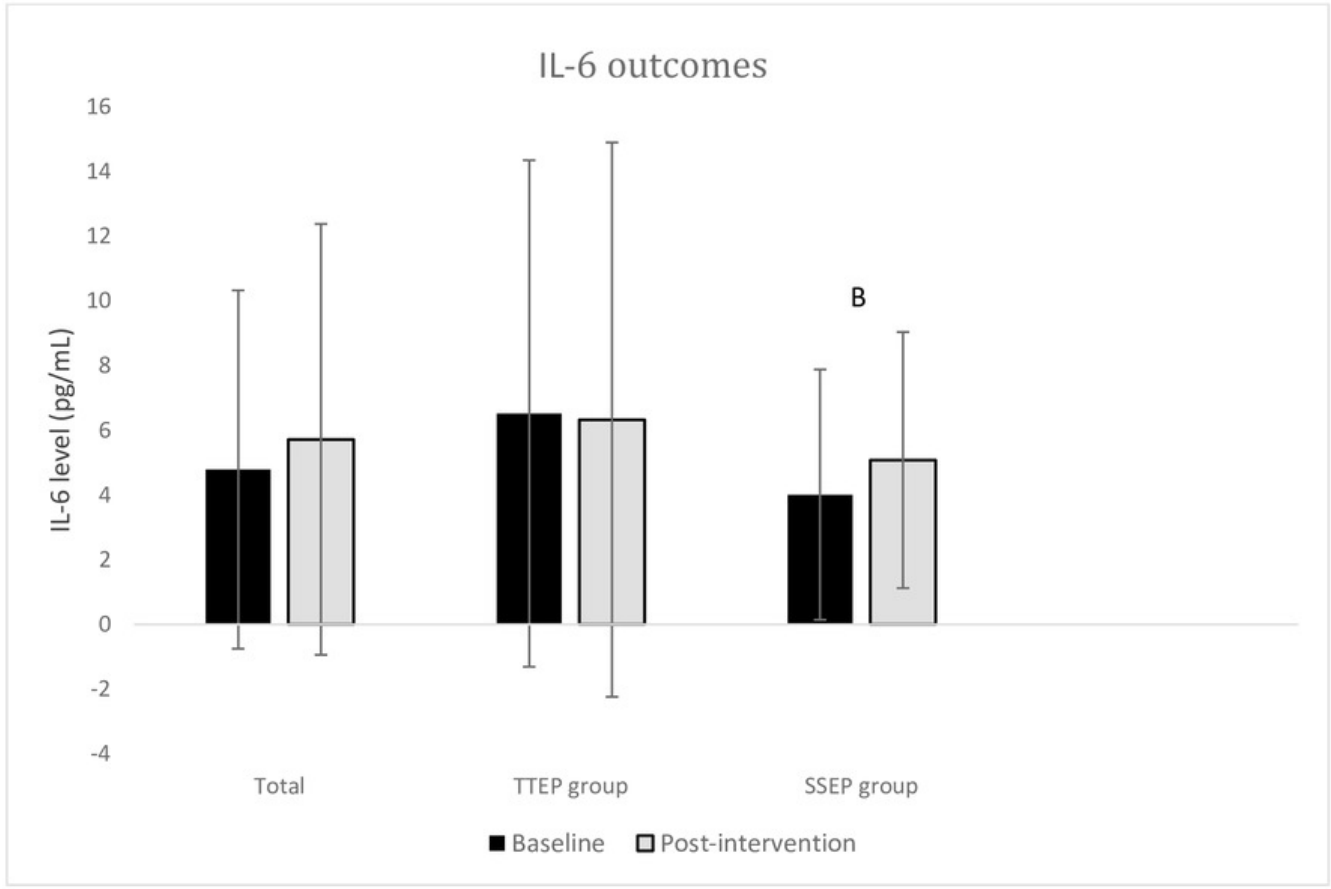




\section{Table $\mathbf{1}$ (on next page)}

Baseline anthropometric and clinical characteristics of the participants.

TTEP = traditional trunk exercise program, SSEP=specific stabilization exercise program, BMI:

body mass index, MET: metabolic equivalent of task 


\begin{tabular}{lccc}
\hline Characteristic & $\begin{array}{c}\text { Total } \\
(\mathrm{n}=30)\end{array}$ & $\begin{array}{c}\text { TTEP Group } \\
(\mathrm{n}=15)\end{array}$ & $\begin{array}{c}\text { SSEP Group } \\
(\mathrm{n}=15)\end{array}$ \\
\hline Age (yr), mean (SD) & $50.5(10.2)$ & $50.9(11.0)$ & $50.1(9.8)$ \\
Height (m), mean (SD) & $1.6(0.1)$ & $1.6(0.1)$ & $1.6(0.1)$ \\
Weight (kg), mean (SD) & $68.8(9.8)$ & $66.8(9.4)$ & $70.9(10.0)$ \\
BMI (kg/m), mean (SD) & $26.9(3.6)$ & $26.3(3.5)$ & $27.5(3.7)$ \\
Grade of physical activity (METS), mean (SD) & $13.5(19.0)$ & $6.8(6.3)$ & $19.7(24.5)$ \\
Pain (cm), mean (SD) & $6.5(1.4)$ & $6.4(1.2)$ & $6.5(1.6)$ \\
Disability (points), mean (SD) & $9.2(3.9)$ & $8.9(4.1)$ & $9.5(3.9)$ \\
\hline
\end{tabular}

1 


\section{Table 2 (on next page)}

Mean (SD) for outcomes reported at all study visits for total and each group, significant differences between visits within groups, $p$ values, mean difference $(95 \% \mathrm{Cl})$ and effect size $(95 \% \mathrm{Cl})$ between groups for pain intensity and disability

TTEP= traditional trunk exercise program, SSEP= specific stabilization exercise program, VAS: visual analogue scale, NRS: numerical rating scale, RMDQ = Roland Morris disability questionnaire, $\mathrm{p}<0.05=$ significant difference between groups, $\mathrm{Cl}=$ Confidence Interval $^{1}$ Baseline (session 0). ${ }^{2}$ Half intervention (session 10). ${ }^{3}$ Post-intervention (session 20). ${ }^{4} \mathrm{~A}$ month post-intervention. ${ }^{a}$ Significant difference from session $0 .{ }^{b}$ Significant difference from

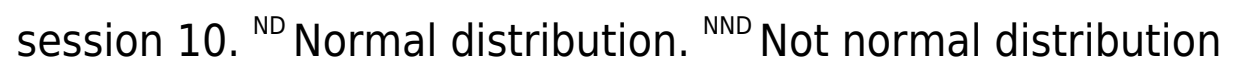




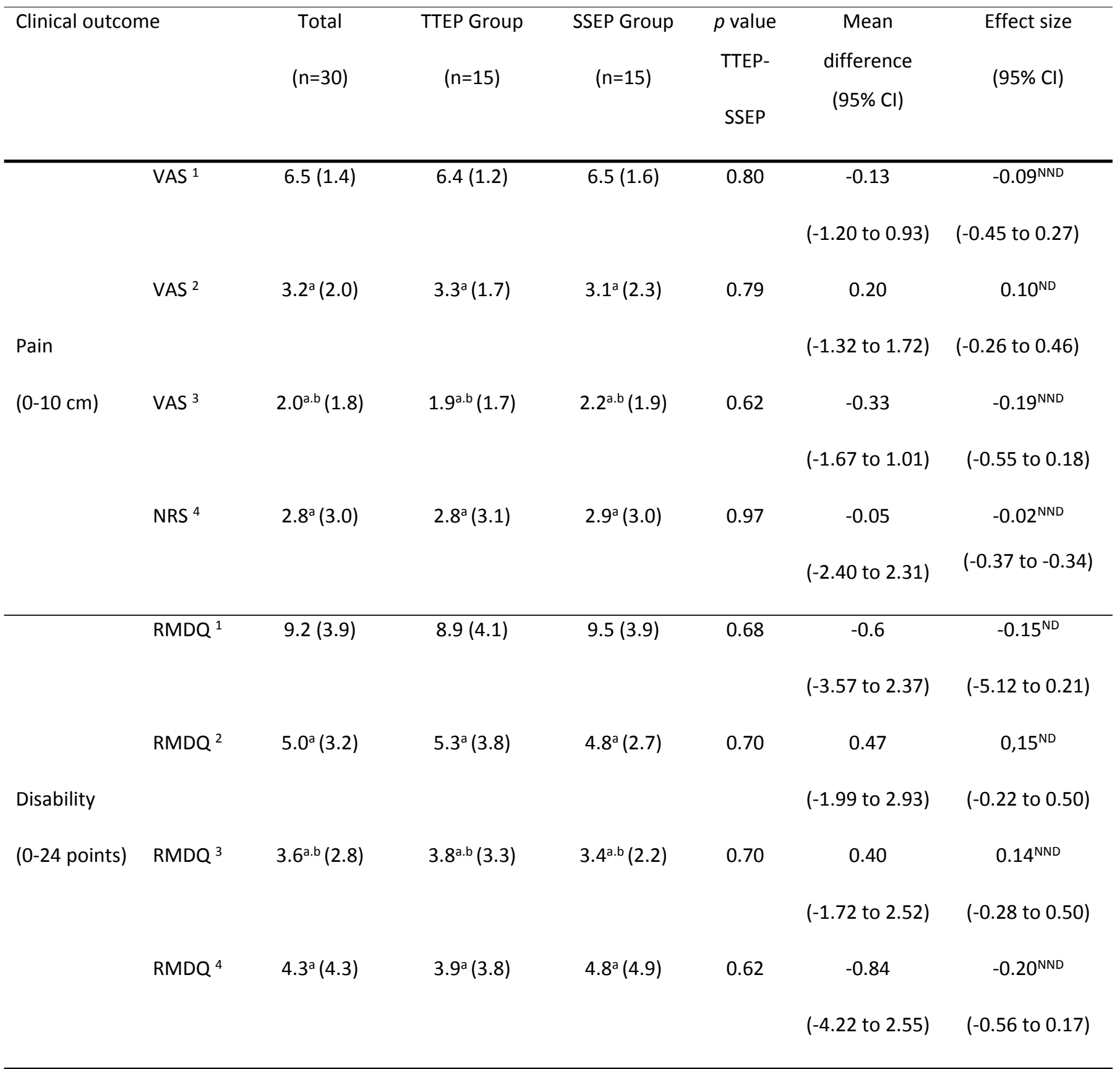

